\section{ABSTRACT}

Introduction: Extended Forsteo® Observational Study (ExFOS), a multinational, noninterventional, prospective, observational study, designed to evaluate fractures, back pain (BP), adherence and health-related quality of life (QoL) in teriparatide (TPTD) treated patients, based on the extension of treatment duration (24 months) and the addition of new indications (glucocorticoid-induced and male osteoporosis) was compared with EFOS.

Methods/design: Baseline data showed that Hellenic EFOS patients share similarities and noticeable differences with female ExFOS patients ${ }^{1}$. To further evaluate such similarities / differences between the two studies, we aimed to compare the active treatment results of the Greek cohorts between EFOS $2(\mathrm{~N}=301$, all female) and ExFOS ( $\mathrm{N}=416,92.1 \%$ female). No statistical comparisons between studies were performed. Results: Approximately $80 \%$ of patients in both cohorts were on treatment one month before maximum treatment period. Lumbar T-score (mean+SD) increased from $-3.46 \pm 0.67(\mathrm{~N}=175)$ at baseline to $-2.54 \pm 0.74(\mathrm{~N}=120)$ at study end in EFOS and from $-3.39 \pm 0.73 \quad(\mathrm{~N}=263)$ to $2.36 \pm 0.63(\mathrm{~N}=78)$ in ExFOS. QoL and BP parameters had similar improvements, as shown by examples depicted below:

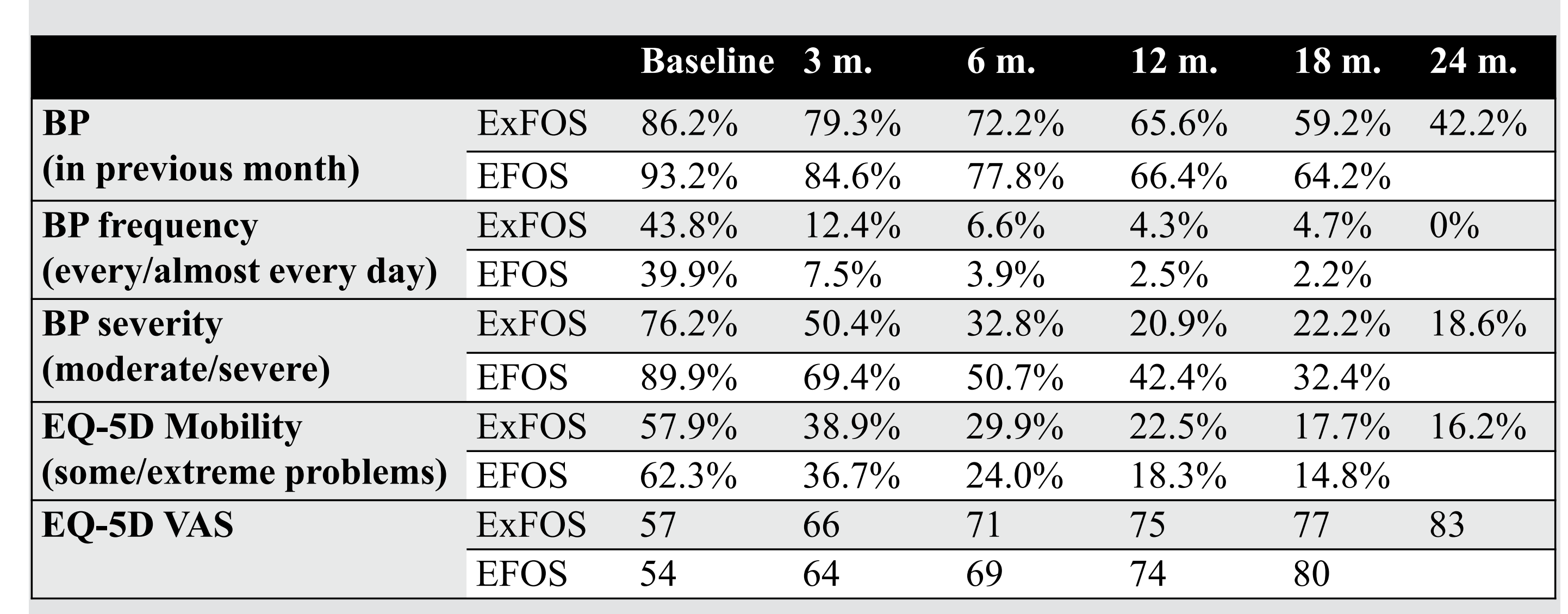

Conclusions: Two similarly designed studies, in comparable Hellenic populations, yielded similar results that should be interpreted in the context of observational studies

\section{INTRODUCTION}

Extended Forsteo ${ }^{\circledR}$ Observational Study (ExFOS), a multinational, non-interventional, prospective, observational study, designed to evaluate fractures, back pain (BP), adherence and healthrelated quality of life (QoL) in teriparatide (TPTD) treated patients, based on the extension of treatment duration (24 months) and the addition of new indications (glucocorticoid-induced and male osteoporosis) was compared with EFOS ${ }^{1-3}$.

\section{METHODS}

Baseline data showed that Hellenic EFOS patients share similarities and noticeable differences with female ExFOS patients ${ }^{1}$.

To further evaluate the effect of the similarities / differences between the two studies on the response to therapy, we aimed to juxtapose the active treatment results of the Greek cohorts between $\operatorname{EFOS}^{2}(\mathrm{~N}=301$, all female) and ExFOS $(\mathrm{N}=416, \quad 92.1 \% \quad$ female $)$. No statistical comparisons were performed.

\section{RESULTS}

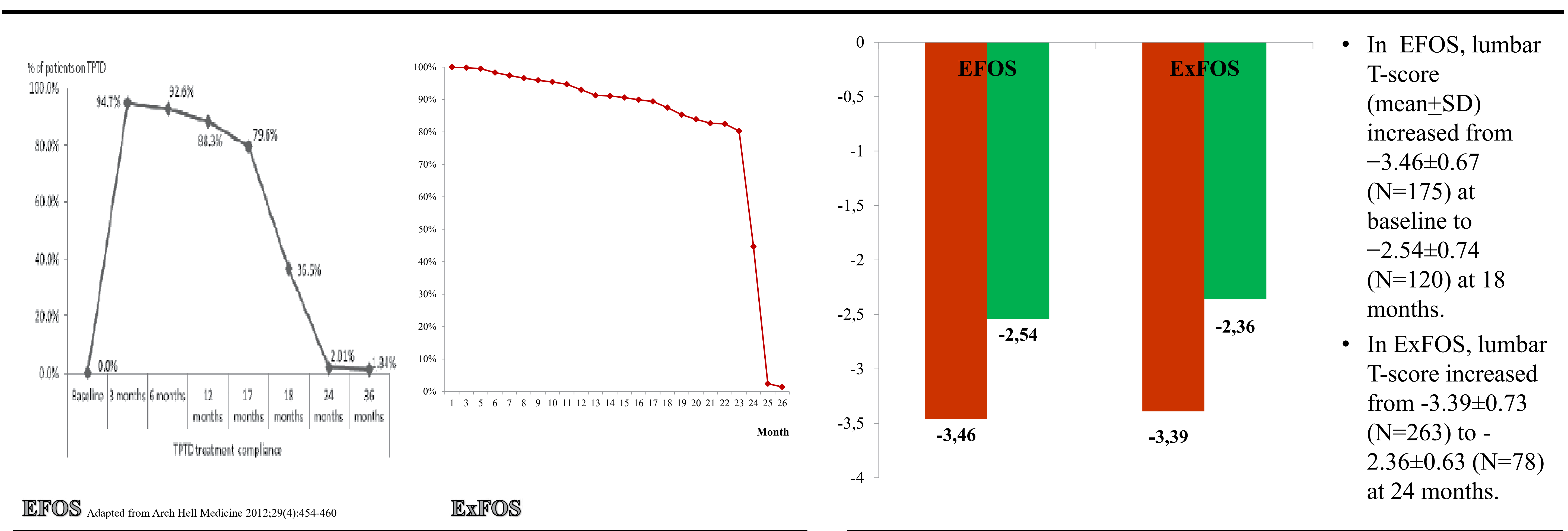

Compliance: Percent of Patients Still Taking Forsteo ${ }^{8}$ by Month Approximately $80 \%$ of Greek patients in both cohorts were on treatment one

Lumbar BMD at baseline and treatment endpoint in EFOS (0-18 months) and ExFOS (0-24 months)

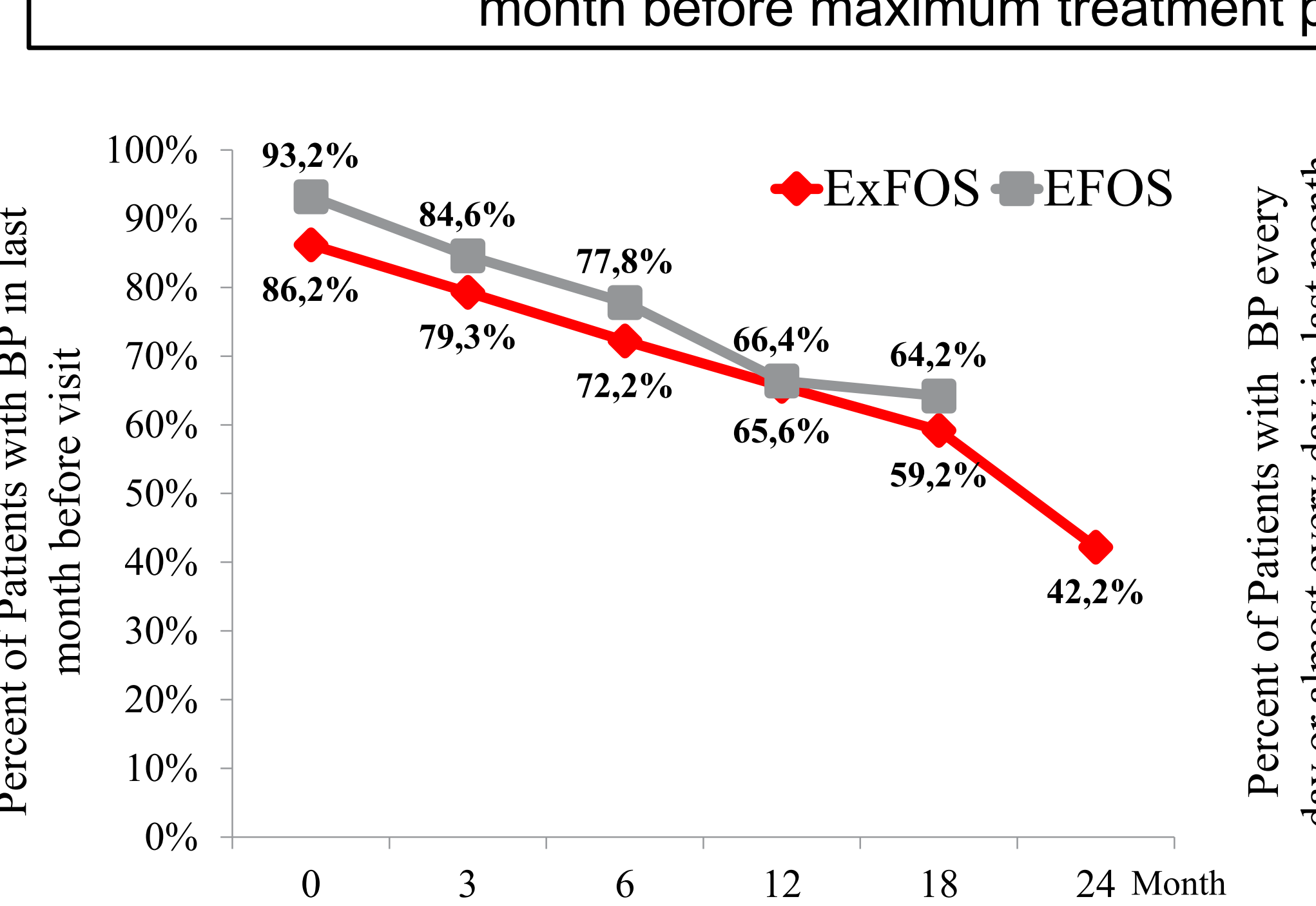

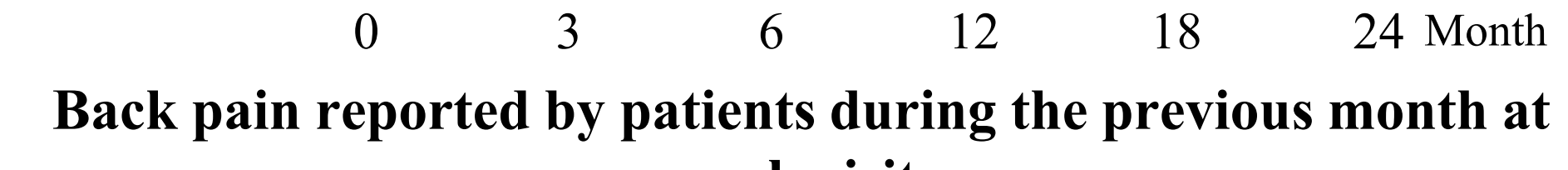
each visit

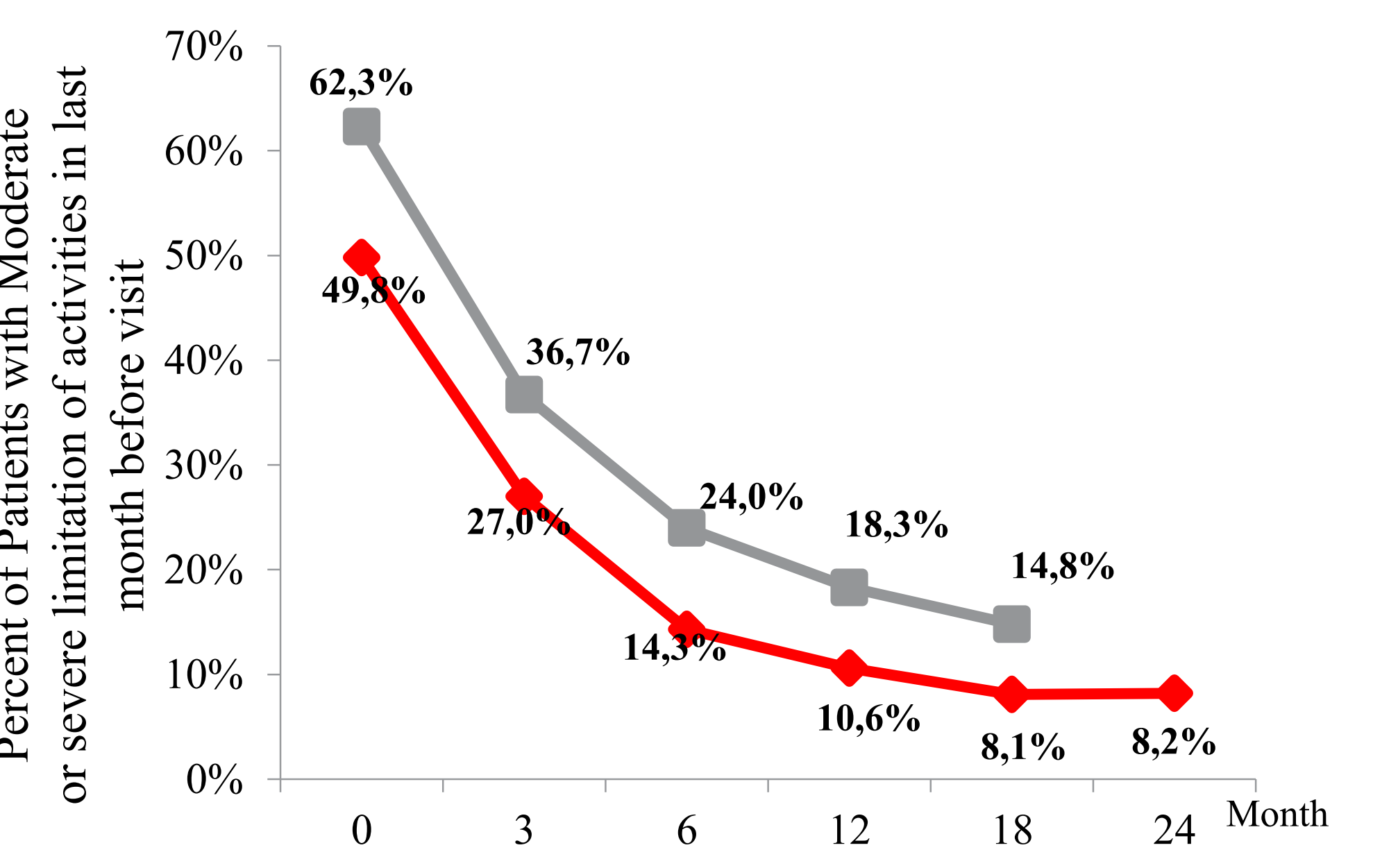

or severe limitation of activities reported
during the previous month at each visit

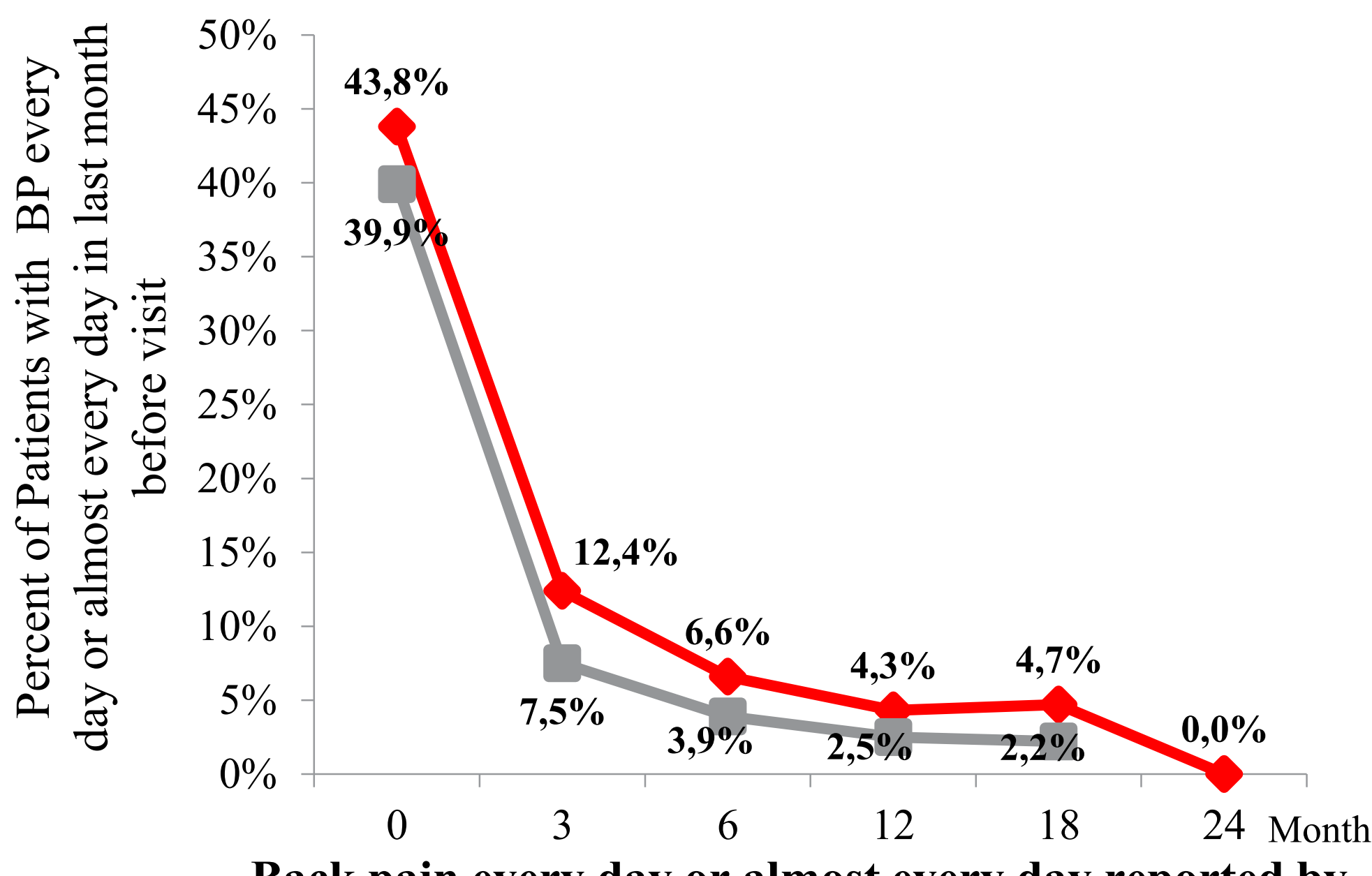

Back pain every day or almost every day reported by

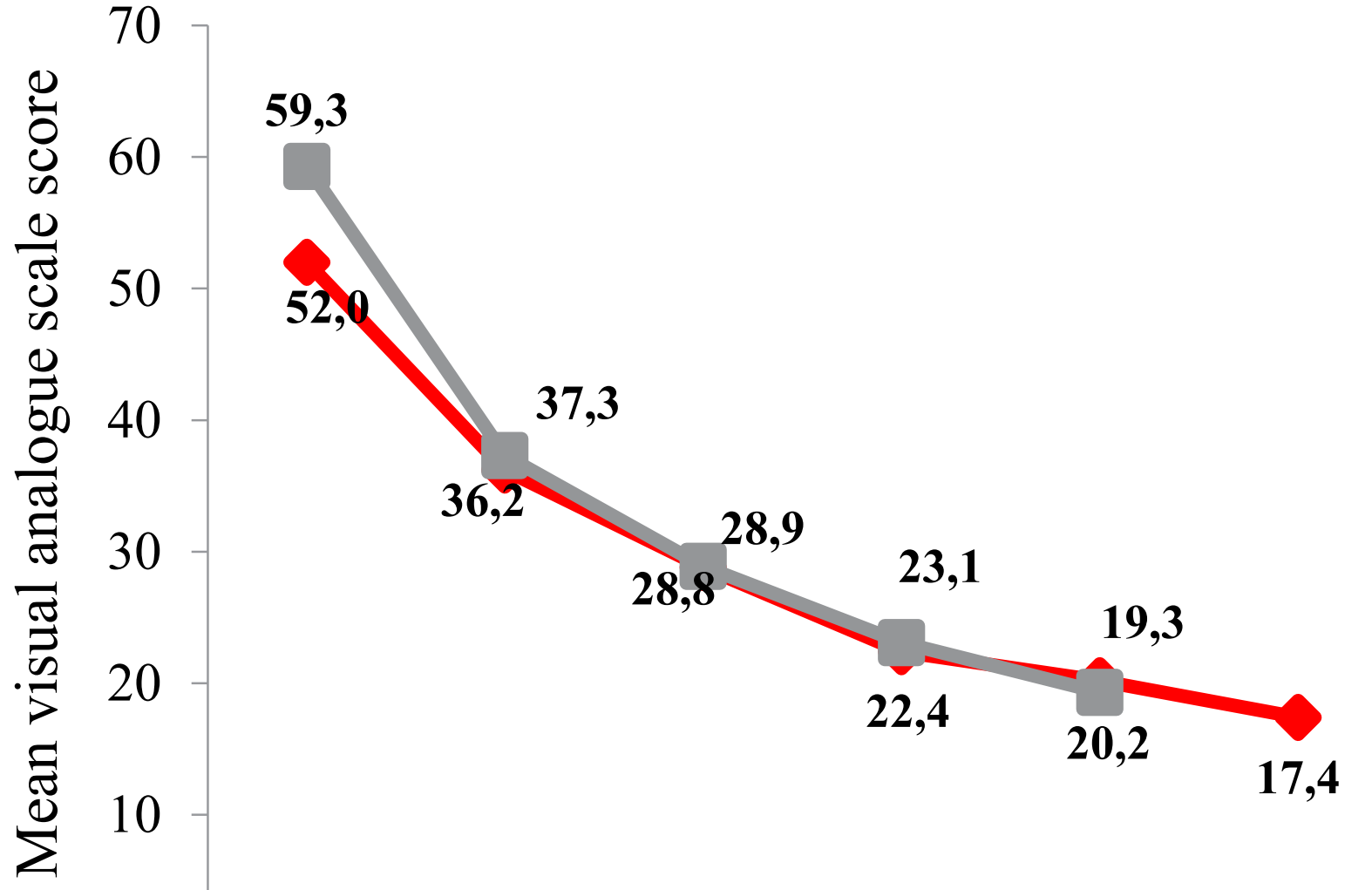

$\begin{array}{ccccccc}0 & 3 & 6 & 12 & 18 & 24 & \text { Month } \\ \text { Mean back pain defined by patients through the BP }\end{array}$ visual analogue scale tool $(\mathrm{mm})$

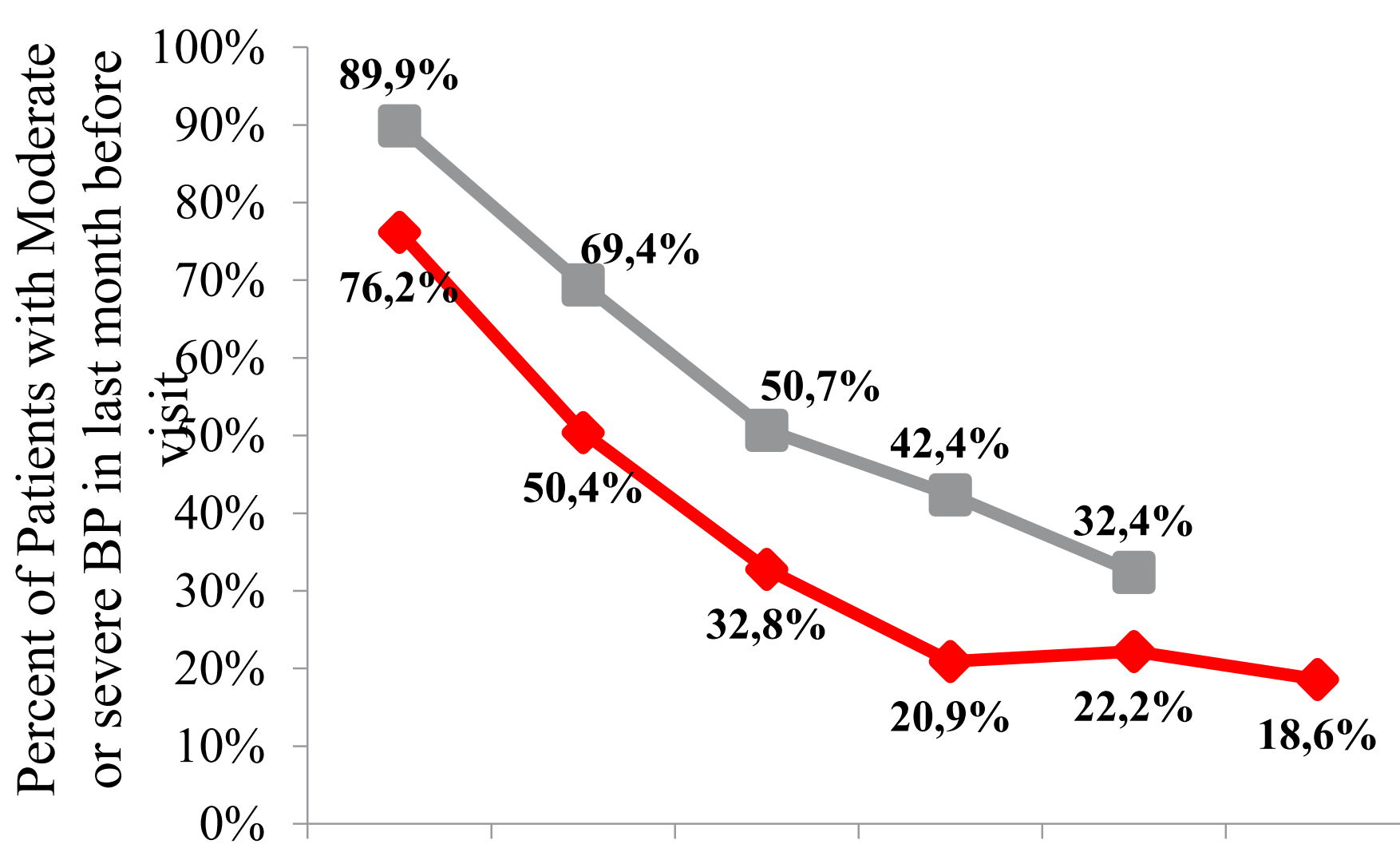
Moderate or severe back pain reported by
patients during the previous month at each visit

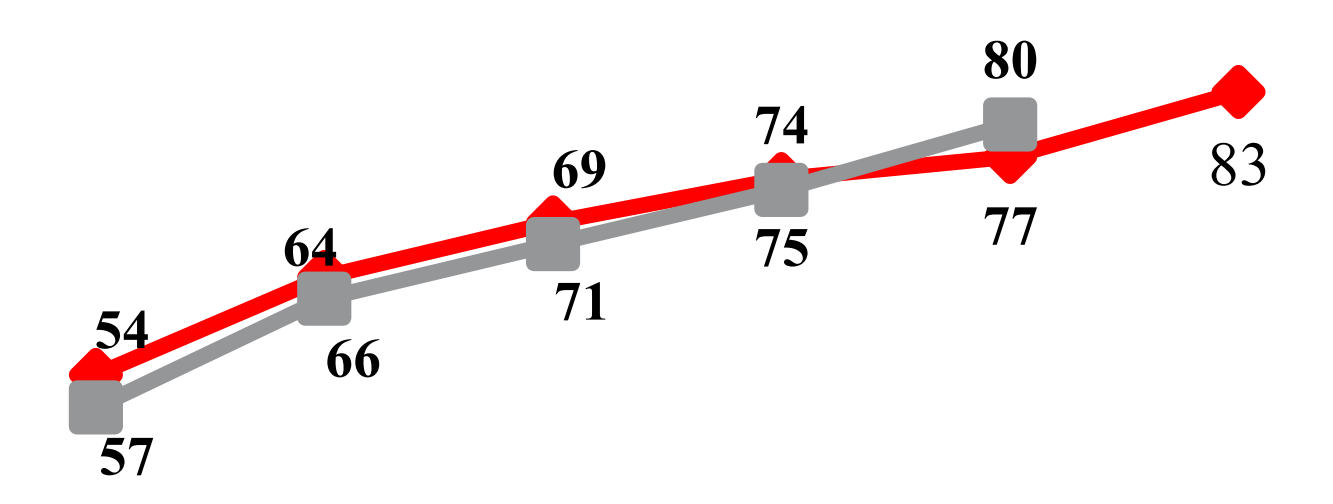

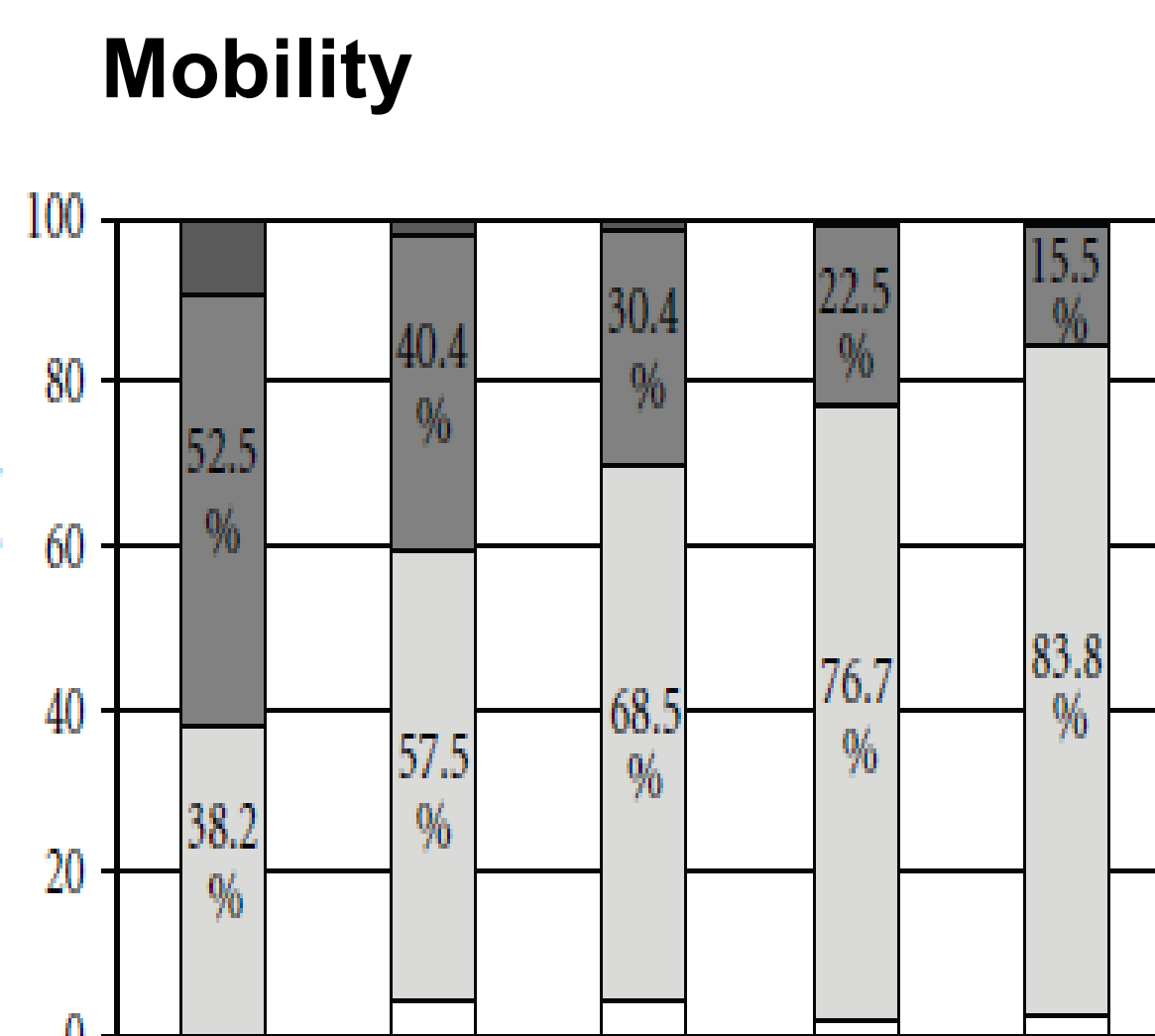

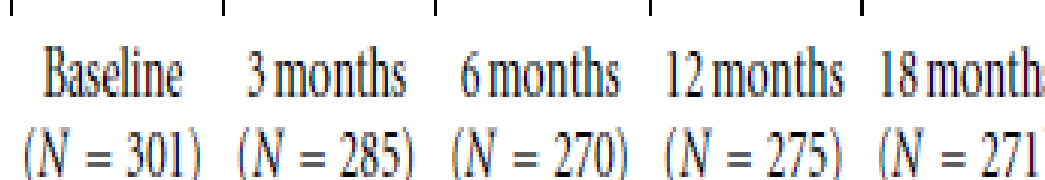

$\begin{array}{ll}\square \text { Missinglunknown } & \square \text { Some problem } \\ \square \text { No problem } & \square \text { Extreme problem }\end{array}$

Usual Activity

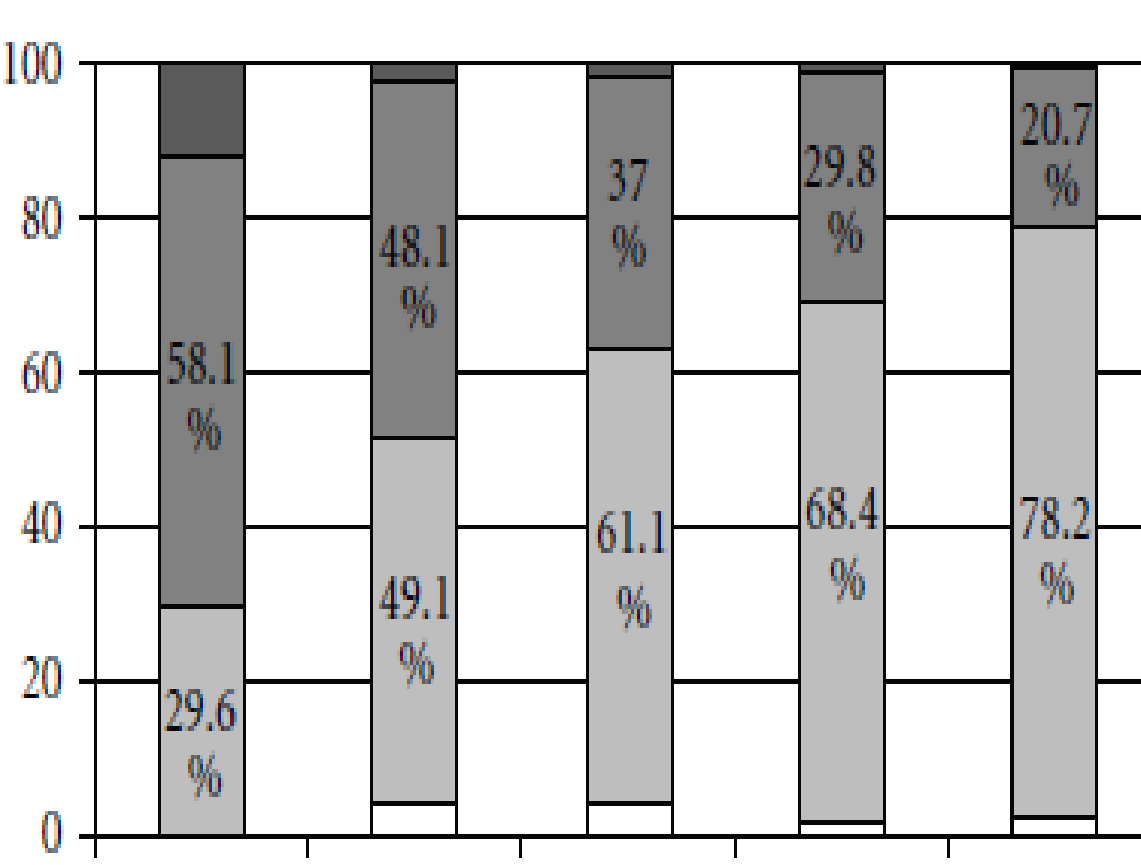

Baseline 3 months 6 months 12 months 18 months
$(N=302)(N=296)(N=283)(N=278)(N=274)$

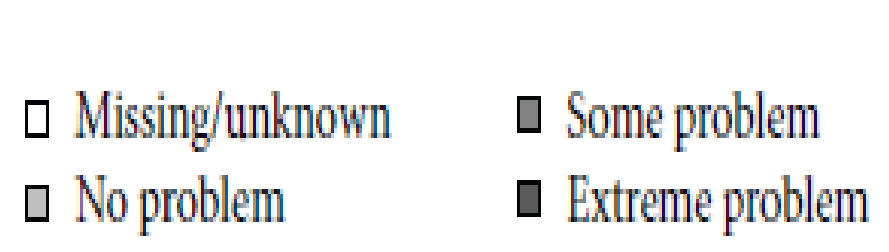

EIFOS
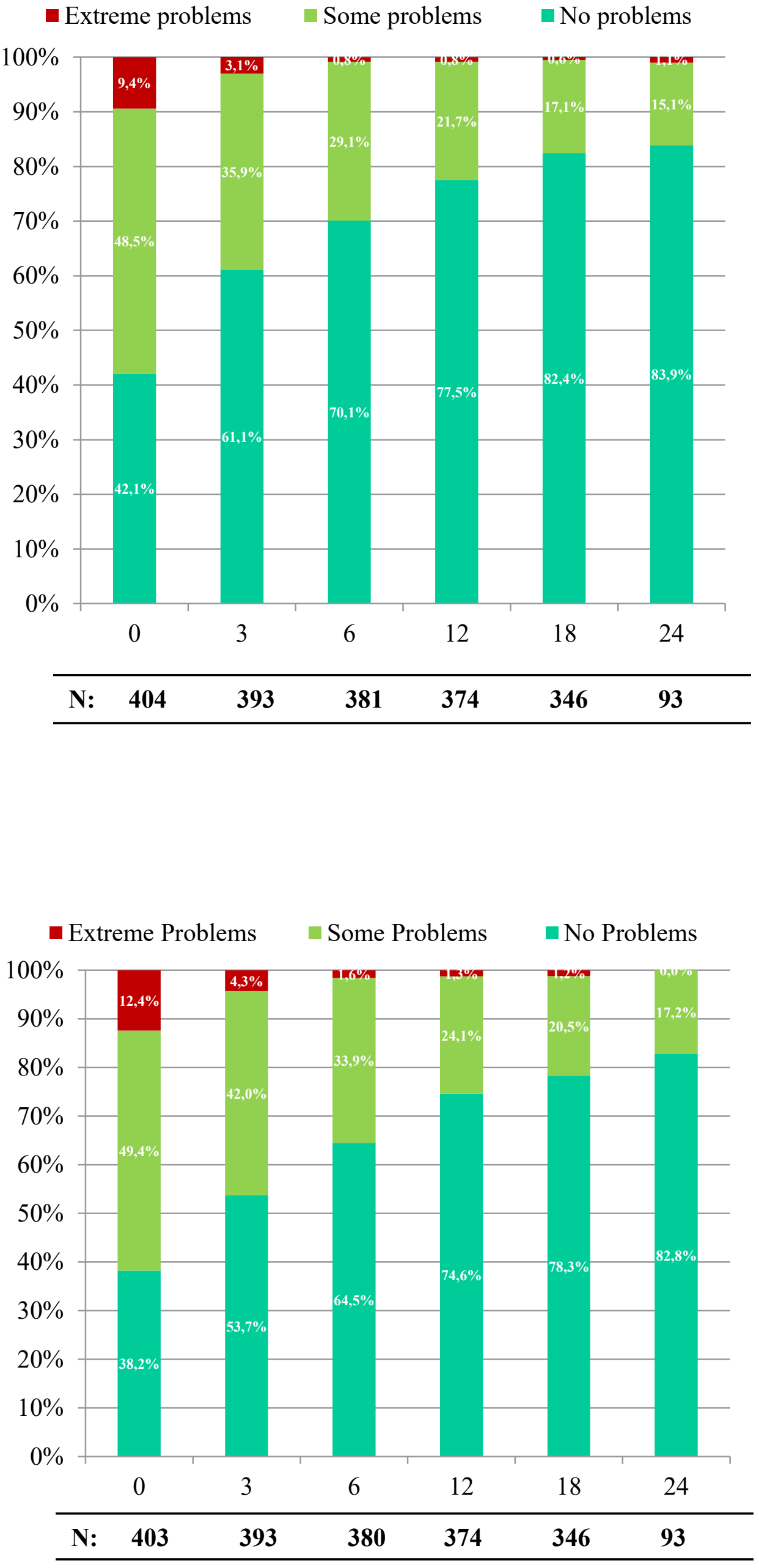

EXIFOS

\title{
EQ-5D parameters
}

EQ5D visual analogue scale (VAS) ${ }^{24 \text { Mon }}$ Pain and discomfort
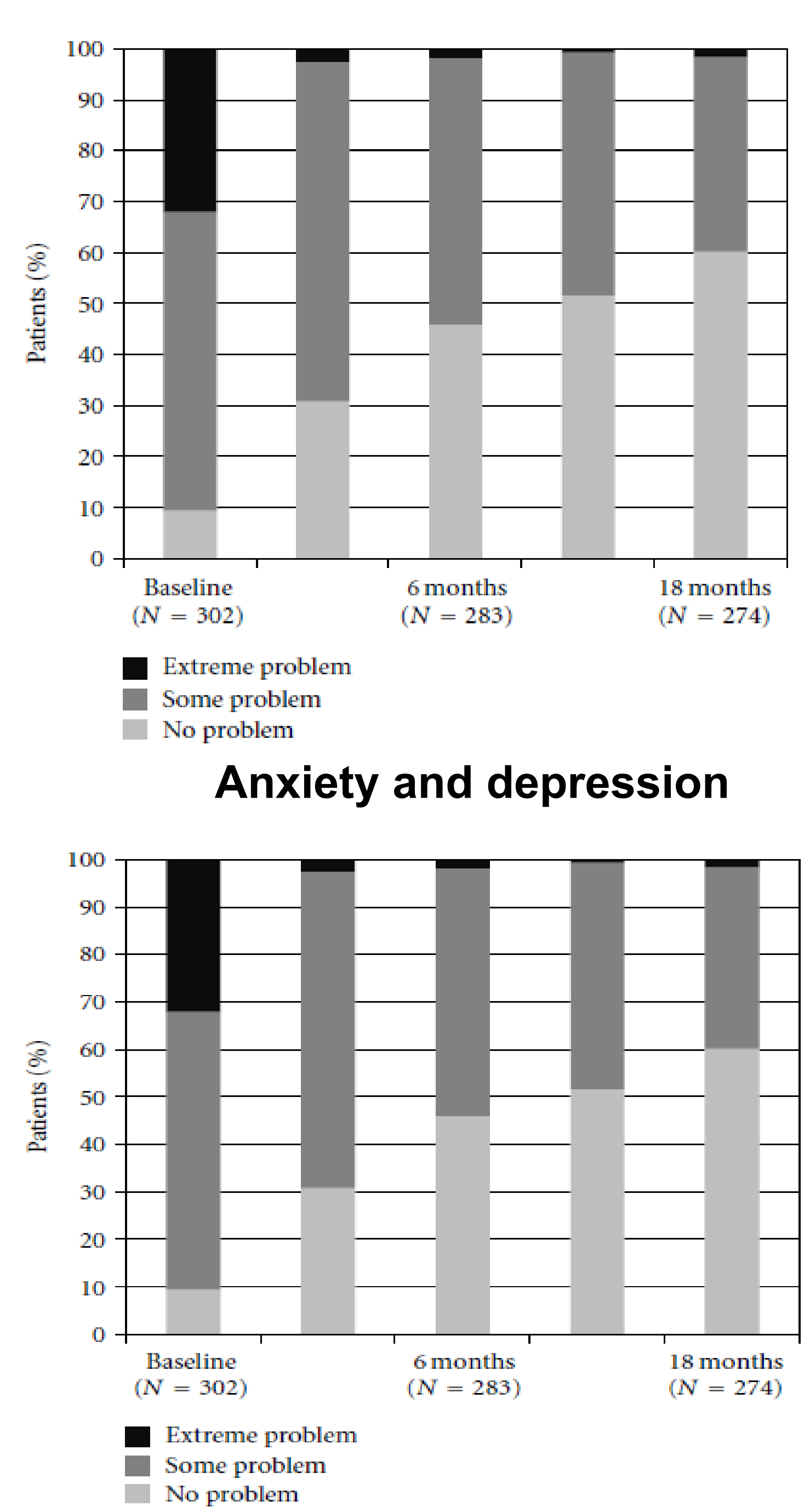

$\mathbb{E} \mathbb{P O S}$
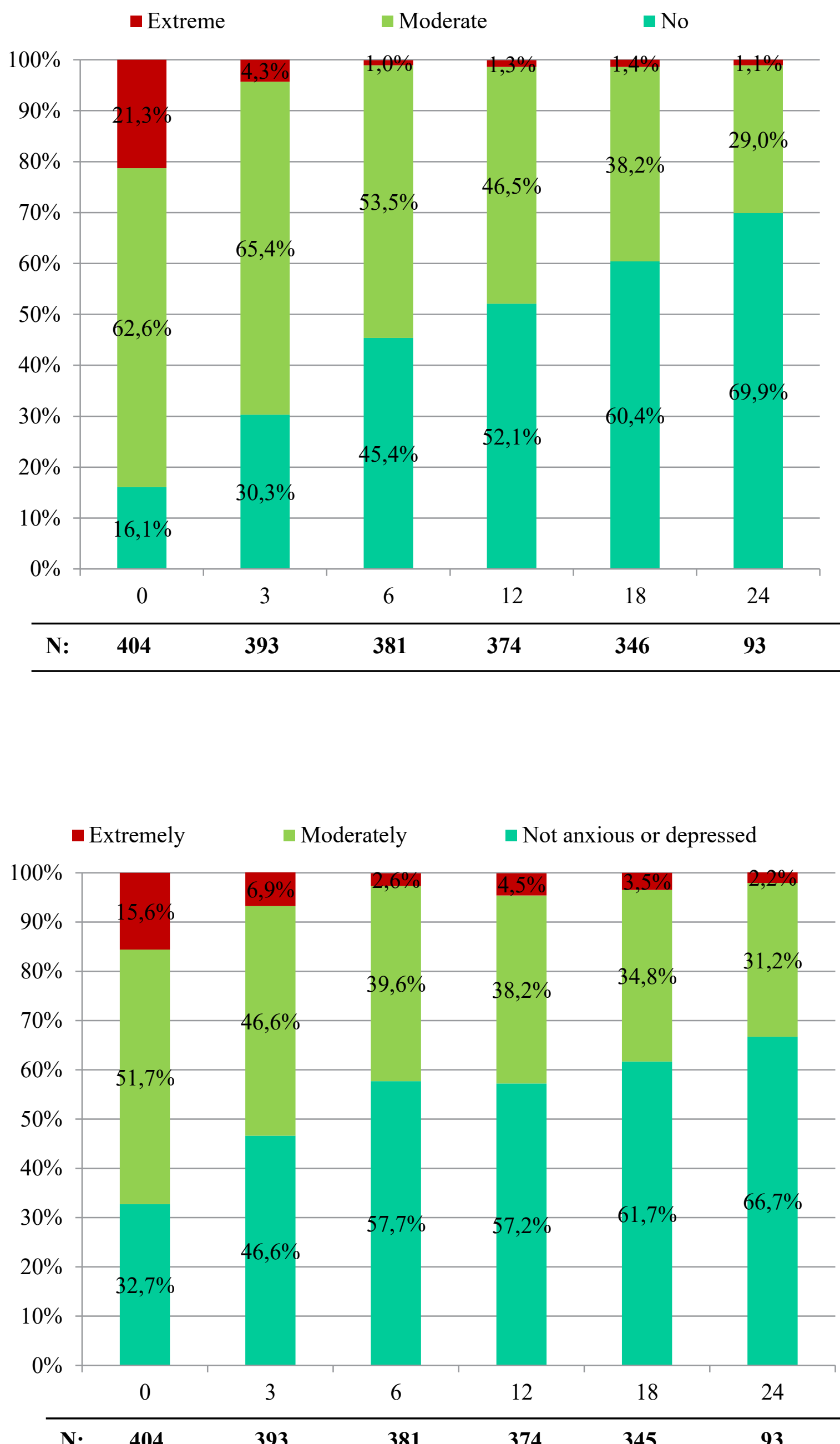

ERIFOS

\section{CONCLUSIONS}

The two studies have differences, for example new indications and extension of treatment period in ExFOS, but overall the design and execution of the studies is quite similar.

In both EFOS and ExFOS we record a parallel increase in BMD, a decrease in back pain parameters and an increase in patient mobility/activity. Additionally, Quality of Life parameters seem to be improving in a similar manner. Results that should be interpreted in the context of observational studies.

\footnotetext{
REFERENCES: ${ }^{1}$ BMC Musculoskelet Disord. 2015;16:136 $\quad$ 2 J Osteoporos. 2011;2011:510398. doi: 10.4061/2011/510398. Epub 2011 Sep 20, ${ }^{3}$ Archives of Hellenic Medicine. 2012;29(4):454-460

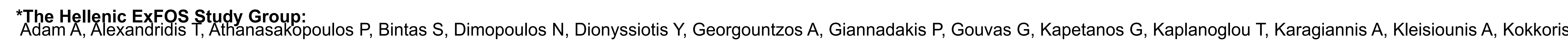

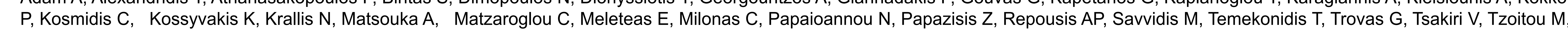
Tzoutzopoulos A, Vandoros G, Ziabaras K 